\title{
Rendimento de grãos e características agronômicas de soja em função de pastagens perenes em sistema de plantio direto
}

\author{
Henrique Pereira dos Santos $\left({ }^{1 *}\right)$; Renato Serena Fontaneli ('); João Leonardo Fernandes Pires ('); \\ Roberto Serena Fontaneli ( $\left.{ }^{2}\right)$; Valdéria Biazus ( $\left.{ }^{3}\right)$; Amauri Colet Verdi $\left({ }^{3}\right)$; Ana Maria Vargas ( $\left.{ }^{3}\right)$ \\ (') Embrapa Trigo, BR 285, km 294, $99001-970$ Passo Fundo (RS), Brasil. \\ (2) Universidade Estadual do Rio Grande do Sul (UERGS), Rua Dr. José Bisognin, 250, 99700-000 Erichim (RS), Brasil. \\ (3) Universidade de Passo Fundo (UPF), Faculdade de Agronomia e Medicina Veterinária (FAMV), BR 285, $99052-900$ Passo Fundo \\ (RS), Brasil. \\ (*) Autor correspondente: henrique.santos@embrapa.br
}

Recebido: 16/maio/2014; Aceito: 20/jun./2014

\begin{abstract}
Resumo
O objetivo do presente estudo foi avaliar o desempenho de soja em sistemas de produção com integração lavoura-pecuária em plantio direto. Constituíram os tratamentos cinco sistemas de produção: sistema I (trigo/soja, ervilhaca/milho e aveia branca/soja); sistema II (trigo/soja, pastagem de aveia preta + ervilhaca/milho e aveia branca/soja); sistema III (pastagens perenes da estação fria: festuca + trevo branco + trevo vermelho + cornichão); sistema IV (pastagens perenes da estação quente: pensacola + aveia preta + azevém + trevo branco + trevo vermelho + cornichão); e sistema V (alfafa). O delineamento experimental foi em blocos ao acaso, com quatro repetições. Não houve diferença entre os sistemas de produção com lavourapecuária para rendimento de grãos, número de legumes/planta, número de grãos/planta, massa de grãos/planta, massa de mil grãos, estatura de plantas e altura de inserção dos primeiros legumes. A soja pode ser cultivada sem prejuízo para rendimento de grãos após aveia branca e trigo, alternando com pastagem de aveia preta + ervilhaca, pastagens perenes de estação fria e de estação quente e alfafa para corte ou pastejo direto.
\end{abstract}

Palavras-chave: alfafa, cornichão, festuca, pensacola, trevos.

\section{Yield and agronomic characteristics on soybean in function of perennial pastures, in no-tillage system}

\begin{abstract}
The objective of this study was to assess grain yield of soybean production systems integrated crop-livestock, under no-tillage. The treatments consisted of five production systems: system I (wheat/soybean, common vetch/corn, and white oat/soybean); system II (wheat/soybean, grazed black oat + grazed common vetch/corn, and white oat/soybean); system III [perennial cool season pastures (fescue + white clover + red clover + birdsfoot trefoil)]; system IV [perennial warm season pastures (bahiagrass + black oat + rye grass + white clover + red clover + birdsfoot trefoil)]; and system V (alfalfa). A randomized complete block design with four replications was used. No difference was found among the production systems integrated crop-livestock to soybean grain yield, number of legume/plant, number of grain/plant, grain mass/plant, 1,000 kernels weight, plant height, and first legumes insertion height. Soybean can be cultivated without grain loss after white oat and wheat alternating with grazed black oat + grazed common vetch, perennial cool-season forages and perennial warm-season forages and alfalfa forages.
\end{abstract}

Key words: alfalfa, birdsfoot trefoil, tall fescue, bahiagrass, clovers.

\section{INTRODUÇÃO}

A integração lavoura-pecuária pode proporcionar vantagens para o agricultor, tais como maior diversificação de atividade, menor consumo de energia e menor risco econômico (Santos et al., 2009b). Além disso, pode propiciar cultivo de várias espécies de inverno e de verão e melhoria da qualidade do solo.
No entanto, a integração lavoura-pecuária impóe desafios para equacionar inúmeras questóes relativas à oferta de forragem adequada aos animais, minimizando o efeito da falta de pastagem nas áreas agrícolas. Desde as primeiras décadas do século passado investe-se na geraçấo de novas tecnologias para o aperfeiçoamento de 
sistemas de produção com integração lavoura-pecuária, envolvendo o desenvolvimento de genótipos diversos, de aveia, de azevém, de centeio e de leguminosas de inverno (Fontaneli et al., 2009). Desde a década de 1990, novas alternativas envolvendo culturas produtoras de grãos (aveia branca, milho, soja e trigo) em rotaçáo com pastagens anuais de inverno (aveia preta, azevém e ervilhaca) e de verão (milheto) ou com pastagens perenes compostas por festuca ou pensacola consorciadas com trevo branco, trevo vermelho e cornichão são pesquisadas (Ambrosio et al., 2001; Santos et al., 2001; 2009a).

De acordo com Balbinot Junior et al. (2009), para que sistemas de produção com integração lavoura-pecuária tenham êxito, alguns fundamentos devem ser levados em conta, como adoção de rotação de culturas, do sistema de plantio direto, uso da genética de animais e de vegetais, da correção da acidez e da fertilidade do solo e, principalmente, do manejo adequado da pastagem. A realização de experimentos de longa duração completos, ou seja, nos quais todas as espécies, tanto de inverno como de verão, se fazem presentes nas parcelas da área experimental, em todas as safras (Santos et al., 2009b), é uma das maneiras de se avaliarem os sistemas de produção com integração lavoura-pecuária. Nesse tipo de estudo pode-se avaliar, por exemplo, o efeito de leguminosas perenes na cultura de soja, em sistema de produçáo com integração lavoura-pecuária.

Os rendimentos de grãos e demais características agronômicas da soja poderão ser afetados quando cultivada após culturas produtoras de grãos intercaladas por pastagens perenes, em períodos de quatro a cinco anos, em comparaçáo com a soja cultivada somente após culturas produtoras de grãos, no inverno. $\mathrm{O}$ presente trabalho teve como objetivo avaliar o efeito de sistemas de produçáo com integraçáo lavoura-pecuária no rendimento de grãos e algumas características agronômicas da soja cultivada sob plantio direto.

\section{MATERIAL E MÉTODOS}

O ensaio foi conduzido no município de Passo Fundo, RS, desde 1993, em Latossolo Vermelho distrófico típico (Streck et al., 2008), de textura argilosa e relevo suave ondulado, em sistema de plantio direto.

Os tratamentos consistiram de cinco sistemas de produção com integração lavoura-pecuária: sistema I (trigo/soja, ervilhaca/milho e aveia branca/soja); sistema II (trigo/ soja, pastagem de aveia preta + ervilhaca/milho e aveia branca/soja); sistema III (pastagens perenes de estação fria: festuca + trevo branco + trevo vermelho + cornichão), depois produção de grãos, como no descrito no sistema I; sistema IV (pastagens perenes de estação quente: pensacola + aveia preta + azevém + trevo branco + trevo vermelho + cornichão), depois produção de grãos, como no descrito no sistema
I; e sistema V (alfafa), depois produção de grãos, como no descrito no sistema I, ou seja, depois de quatro anos de cultivo, metade das parcelas dos sistemas III, IV e V passou para sistemas de produção de grãos, como sistema de produção I, e metade das parcelas desses sistemas continuou com pastagens perenes. Nos quatro anos seguintes houve novamente inversão dos sistemas de produção de grãos com pastagens perenes de estação fria (sistema III), de estação quente (sistema IV) e alfafa (sistema V).

A aveia preta + ervilhaca foi pastejada por uma ou duas vezes por bovinos leiteiros, com alta carga animal, de 15 a 20 novilhas ou vacas leiteiras, visando atingir a altura de resteva num curto período, de um ou dois dias. Os animais iniciavam o pastejo quando as plantas atingiam a estatura de, aproximadamente, $20-30 \mathrm{~cm}$, deixando-se uma altura de resteva de 7 a $10 \mathrm{~cm}$. As pastagens perenes de estação fria, de estação quente e a alfafa foram pastejadas por cinco a sete vezes cada ano, observando-se o mesmo critério para colocar os animais na pastagem de aveia preta + ervilhaca. O critério do início do pastejo na alfafa foi no início do florescimento ou com rebrote basilar de 5 a $7 \mathrm{~cm}$. Nessa ocasião foi avaliado o peso de matéria verde, antes e depois do pastejo, e, posteriormente, o da matéria seca. Após o pastejo da aveia preta + ervilhaca, permitiu-se um rebrote durante 30 a 40 dias, até acumularem-se de 1,5 a 2,0 t de matéria seca, para, então, realizar-se a dessecação e semearse o milho.

As culturas, tanto de inverno como de verão, foram estabelecidas em sistema de plantio direto. As cultivares de soja usada foram: BR 16, em 1996/1997 e 1997/1998, BRS 137 , em 1999/2000 e 2000/2001, BRS 154, em 2001/2002 e 2003/2004, BRS 153, em 2004/2005, BRS 244 RR, em 2005/2006, BRS Charrua RR, em 2006/2007, BRS 255 RR, de 2007/2008 a 2009/2010, BRS Tertúlia, em 2010/2011, e Apolo, em 2011/2012, semeadas em época única. Na safra de 1998/1999 e 2002/2003, a soja não foi colhida, em virtude da seca.

A adubação de manutenção foi realizada de acordo com a indicaçáo para soja e baseada nos resultados da análise de solo (SBCS, 2004). As amostras de solo foram coletadas a cada três anos, após colheita das culturas de verão.

A época de semeadura e o controle de plantas daninhas seguiram as indicaçóes para a cultura de soja. A colheita da cultura de soja foi efetuada com colhedora automotriz especial para parcelas experimentais. A área da parcela foi de $45 \mathrm{~m}^{2}$ (20,0 $\mathrm{m}$ de comprimento por 2,25 $\mathrm{m}$ de largura). O rendimento de grãos de soja foi avaliado a partir da colheita de área de $27 \mathrm{~m}^{2}$, corrigindo-se o rendimento para umidade de $13 \%$.

O delineamento experimental foi em blocos ao acaso, com quatro repetições. Foram efetuadas as análises de variância do rendimento de grãos, estatura de plantas, altura de inserção dos primeiros legumes, massa de mil grãos e dos componentes do rendimento (número de legumes, número 
de grãos e massa de grãos/planta) de soja (dentro de cada ano e na média conjunta dos anos) de 1996/1997 a 2011/2012. Os componentes do rendimento de soja foram avaliados em 20 plantas coletadas ao acaso, antes da colheita. Considerouse o efeito do tratamento (culturas antecessoras) como fixo e o efeito do ano como aleatório. Os parâmetros avaliados foram submetidos à análise de variância pelo teste de Tukey a 5\% de significância, com uso do programa estatístico SAS versão 9.2 (SAS INSTITUTE, 2008).

\section{RESULTADOS E DISCUSSÃO}

No período de 1996/1997 a 2011/2012 houve diferença entre as médias de rendimento de grãos, componentes do rendimento (número de legumes/planta, número de grãos/ planta e massa de grãos/planta), massa de mil grãos, estatura de plantas e altura de inserção dos primeiros legumes de soja para o fator ano, indicando que essas características foram afetadas por variaçóes meteorológicas ocorridas entre os anos, ou seja, esses parâmetros variaram entre os anos estudados (Tabelas 1 a 7). Isso comprova os resultados anteriormente obtidos por Santos et al. (2004b; 2013) para essas variáveis, com sistemas de produção em integraçáo lavoura-pecuária.

Porém, na média conjunta das safras de 1996/1997 a 2011/2012 não foram encontradas diferenças entre os sistemas de produção com integração lavoura-pecuária para rendimento de grãos, número de legumes/planta, número de grãos/planta, massa de grãos/planta, massa de mil grãos, estatura de plantas e altura de inserçáo dos primeiros legumes de soja (Tabelas de 1 a 7). Pelo observado, na média conjunta dos dados, essas características não foram influenciadas pelo tipo de resíduo vegetal remanescente de inverno na cultura de soja, ou, quando isso ocorreu, para rendimento de grãos de soja o foram, em anos específicos (2000/2001, 2003/2004, 2004/2005, 2005/2006, 2006/2007, 2009/2010) ou na análise conjunta de 1996/1997 e de 2001/2002 (Santos et al., 2004a).

Na safra de 2000/2001, a soja cultivada após trigo no sistema IV mostrou rendimento de grãos maior do que a soja cultivada após trigo no sistema III. A soja cultivada após aveia branca, em todos os sistemas estudados e após trigo, nos sistemas I, II e V, ficou numa posição intermediária para rendimento de grãos. Até essa safra agrícola não havia diferença para rendimento de grãos de soja (Tabela 1). Deve ser levado em conta que houve pequenas diferenças entre as médias individuais quanto ao rendimento de grãos (de 1996/1997 a 1999/2000, de alguns tratamentos. Em razão da consistência dos dados, essa diferença só foi verdadeira, na análise conjunta dos dados de 1996/1997 a 2001/2002, em relação a esse parâmetro (Santos et al., 2004a).

$\mathrm{Na}$ análise conjunta abrangendo o período de 1996/1997 a 2001/2002, a soja cultivada após aveia branca, nos sistemas I $\left(2.891 \mathrm{~kg} \mathrm{ha}^{-1}\right)$, IV $\left(2.960 \mathrm{~kg} \mathrm{ha}^{-1}\right)$ e V (2.964 $\left.\mathrm{kg} \mathrm{ha}^{-1}\right)$, e após trigo, nos sistemas IV $\left(2.905 \mathrm{~kg} \mathrm{ha}^{-1}\right) \mathrm{eV}\left(2.912 \mathrm{~kg} \mathrm{ha}^{-1}\right)$, mostrou maior rendimento de grãos em relaçáo à soja cultivada após aveia branca $\left(2.581 \mathrm{~kg} \mathrm{ha}^{-1}\right)$ e trigo $\left(2.645 \mathrm{~kg} \mathrm{ha}^{-1}\right)$, no sistema III (Santos et al., 2004a). A soja cultivada após

Tabela 1. Rendimento de grãos de soja em sistemas de produção com integração lavoura-pecuária, em Passo Fundo, RS

\begin{tabular}{|c|c|c|c|c|c|c|c|c|c|c|c|}
\hline \multirow{3}{*}{ Ano } & \multicolumn{10}{|c|}{ Sistema de produção } & \multirow{3}{*}{ Média } \\
\hline & \multicolumn{2}{|c|}{ Sistema I } & \multicolumn{2}{|c|}{ Sistema II } & \multicolumn{2}{|c|}{ Sistema III } & \multicolumn{2}{|c|}{ Sistema IV } & \multicolumn{2}{|c|}{ Sistema V } & \\
\hline & $\mathbf{A b}$ & $T$ & $A b$ & $\mathbf{T}$ & $\mathbf{A b}$ & $T$ & $A b$ & T & $\mathbf{A b}$ & T & \\
\hline \multicolumn{12}{|c|}{ Rendimento de grãos (kg ha-1) } \\
\hline 1996/97 & 2.047 & 2.232 & 2.137 & 2.167 & 1.921 & 2.007 & 2.080 & 2.132 & 1.975 & 1.860 & $2.056 \mathrm{fg}$ \\
\hline 1997/98 & 3.180 & 2.974 & 3.256 & 2.956 & 2.622 & 2.668 & 2.974 & 2.918 & 3.032 & 3.023 & $2.960 \mathrm{~b}$ \\
\hline 1999/00 & 3.219 & 3.060 & 3.296 & 3.080 & 3.141 & 3.401 & 3.704 & 3.393 & 3.679 & 3.383 & $3.335 \mathrm{a}$ \\
\hline $2000 / 01$ & $3.291 \mathrm{ab}$ & $3.318 \mathrm{ab}$ & $3.222 \mathrm{ab}$ & $3.256 \mathrm{ab}$ & $3.178 \mathrm{ab}$ & $2.971 \mathrm{~b}$ & $3.519 \mathrm{ab}$ & $3.640 \mathrm{a}$ & $3.486 \mathrm{ab}$ & $3.383 \mathrm{ab}$ & $3.326 \mathrm{a}$ \\
\hline $2001 / 02$ & 2.720 & 2.615 & 2.410 & 2.273 & 2.042 & 2.177 & 2.525 & 2.444 & 2.646 & 2.910 & $2.476 \mathrm{de}$ \\
\hline $2003 / 04$ & $1.817 b$ & $1.521 \mathrm{~b}$ & $1.456 \mathrm{~b}$ & $1.441 \mathrm{~b}$ & $1.955 a b$ & $1.967 \mathrm{ab}$ & $1.911 \mathrm{ab}$ & $1.935 a b$ & $2.177 \mathrm{a}$ & $2.110 \mathrm{a}$ & $1.830 \mathrm{~g}$ \\
\hline $2004 / 05$ & $896 a b c$ & $945 a b$ & $818 a b c$ & $975 a$ & $650 \mathrm{abc}$ & $762 a b c$ & $550 \mathrm{bc}$ & $749 a b c$ & $515 c$ & $618 a b c$ & $748 \mathrm{~h}$ \\
\hline $2005 / 06$ & $2.100 \mathrm{bc}$ & $2.069 b c$ & 2.152 bc & $2.146 b c$ & 1.962 c & $3.038 \mathrm{a}$ & $2.521 \mathrm{abc}$ & $2.807 a b$ & $1.919 \mathrm{c}$ & 2.208 bc & 2.292 ef \\
\hline 2006/07 & $2.789 a b$ & $1.932 \mathrm{C}$ & $2.401 \mathrm{abc}$ & $2.148 b c$ & $2.327 a b c$ & $2.156 \mathrm{bc}$ & 1.632 c & 2.158 bc & $2.917 \mathrm{ab}$ & $3.123 \mathrm{a}$ & $2.358 \mathrm{de}$ \\
\hline 2008/09 & 2.671 & 2.309 & 2.655 & 2.423 & 2.490 & 2.725 & 2.799 & 2.837 & 2.519 & 2.489 & $2.592 \mathrm{~cd}$ \\
\hline $2009 / 10$ & $2.480 a b$ & $2.391 \mathrm{ab}$ & $2.306 a b$ & $2.252 \mathrm{~b}$ & $2.331 \mathrm{ab}$ & $2.300 \mathrm{ab}$ & $2.762 a b$ & $2.894 \mathrm{a}$ & $2.453 \mathrm{ab}$ & $2.491 \mathrm{ab}$ & $2.466 \mathrm{de}$ \\
\hline $2010 / 11$ & 2.007 & 2.121 & 2.169 & 2.119 & 2.518 & 2.173 & 2.606 & 2.361 & 2.406 & 2.224 & 2.270 ef \\
\hline $2011 / 12$ & 2.852 & 2.853 & 3.024 & 3.084 & 2.633 & 2.915 & 3.118 & 3.037 & 2.551 & 2.534 & $2.860 \mathrm{bc}$ \\
\hline Média & 2.467 & 2.334 & 2.408 & 2.332 & 2.290 & 2.405 & 2.515 & 2.562 & 2.483 & 2.489 & 2.428 \\
\hline
\end{tabular}

1996/97: C.V.: 10\% e F.: 1,3ns; 1997/98: C.V.: 10\% e F.: 1,8ns; 1999/00: C.V.: 15\% e F.: 0,8ns; 2000/01: C.V.: 8\% e F.: 2,3*; 2001/02: C.V.: 15\% e F.: 1,9ns; 2003/04: C.V.: 12\% e F.: 5,4**; 2004/05: C.V.: 22\% e F.: 3,7**; 2005/06: C.V.: 14\% e F.: 5,1**; 2006/07: C.V.: 1\% e F.: 7,3**; 2008/09: C.V.: 14\% e F.: 1,6ns; 2009/10: C.V.: 11\% e F.: 2,5*; 2010/11.: C.V.: 11\% e F.: 2,5ns; e 2011/12: C.V.: 13\% e F.: 1,4ns; Sistema I: trigo/soja, ervilhaca/milho e aveia branca/soja; Sistema II: trigo/soja, pastagem de aveia preta + ervilhaca/milho e aveia branca/soja; Sistema III: pastagem perene de estação fria (festuca + trevos + cornichão), depois produção de grãos; Sistema IV: pastagem perene de estação quente (pensacola + trevos + cornichăo + aveia preta + azevém), depois produção de grăos; e Sistema V: alfafa, depois produçăo de grăos; Ab: aveia branca e T: trigo; Médias seguidas de mesma letra, minúscula na vertical e maiúscula na horizontal, não apresentam diferenças significativas ao nível de $5 \%$ de significância, pelo teste de Tukey; ns: não significativo; *: nível de significância de $5 \%$; ** nível de significância de $1 \%$. 
aveia branca no sistema II (2.864 $\left.\mathrm{kg} \mathrm{ha}^{-1}\right)$ e após trigo nos sistemas I $\left(2.840 \mathrm{~kg} \mathrm{ha}^{-1}\right)$ e II $\left(2.746 \mathrm{~kg} \mathrm{ha}^{-1}\right)$ ficou numa posição intermediária para rendimento de grãos. Nesse caso, a soja cultivada após leguminosas perenes de estação quente e após a alfafa mostrou rendimento de grãos mais elevado.
Nesse período e em outros estudos, os resíduos remanescentes têm desempenhado importante papel no sistema de plantio direto como, por exemplo, no controle da erosão, na conservação da fertilidade e na umidade do solo (Flores et al., 2008; Potes et al., 2010; Souza et al., 2009).

Tabela 2. Número de legumes/planta de soja em sistemas de produção com integração lavoura-pecuária, em Passo Fundo, RS

\begin{tabular}{|c|c|c|c|c|c|c|c|c|c|c|c|}
\hline \multirow{3}{*}{ Ano } & \multicolumn{10}{|c|}{ Sistema de produção } & \multirow{3}{*}{ Média } \\
\hline & \multicolumn{2}{|c|}{ Sistema I } & \multicolumn{2}{|c|}{ Sistema II } & \multicolumn{2}{|c|}{ Sistema III } & \multicolumn{2}{|c|}{ Sistema IV } & \multicolumn{2}{|c|}{ Sistema V } & \\
\hline & $A b$ & $\mathbf{T}$ & Ab & $\mathbf{T}$ & $\mathbf{A b}$ & $\mathbf{T}$ & $\mathbf{A b}$ & $\mathbf{T}$ & $\mathbf{A b}$ & $\mathbf{T}$ & \\
\hline \multicolumn{12}{|c|}{ Número de legumes/planta de soja } \\
\hline 1996/97 & 37 & 39 & 36 & 40 & 38 & 36 & 36 & 36 & 41 & 41 & 38 de \\
\hline $1997 / 98$ & $41 \mathrm{ab}$ & $37 \mathrm{~b}$ & $46 \mathrm{ab}$ & $40 a b$ & $47 \mathrm{ab}$ & $41 \mathrm{ab}$ & $45 a b$ & $46 a b$ & $57 \mathrm{a}$ & $55 \mathrm{ab}$ & 46 bc \\
\hline 1999/00 & 25 & 28 & 27 & 28 & 30 & 27 & 30 & 32 & 27 & 30 & $29 \mathrm{fg}$ \\
\hline $2000 / 01$ & 45 & 44 & 53 & 51 & 47 & 51 & 44 & 44 & 50 & 48 & $48 \mathrm{~b}$ \\
\hline $2001 / 02$ & 54 & 71 & 58 & 63 & 51 & 49 & 49 & 55 & 44 & 60 & $56 a$ \\
\hline $2003 / 04$ & 22 & 26 & 23 & 28 & 26 & 24 & 31 & 33 & 26 & 28 & $27 \mathrm{fgh}$ \\
\hline $2004 / 05$ & 38 & 29 & 37 & 47 & 30 & 44 & 53 & 38 & 33 & 28 & $38 \mathrm{de}$ \\
\hline $2005 / 06$ & 35 & 46 & 39 & 33 & 31 & 43 & 39 & 39 & 45 & 41 & $39 \mathrm{~cd}$ \\
\hline $2006 / 07$ & 27 & 22 & 24 & 24 & 22 & 21 & 26 & 23 & 25 & 25 & $24 \mathrm{gh}$ \\
\hline 2008/09 & 23 & 18 & 23 & 20 & 19 & 19 & 24 & 20 & 23 & 26 & $21 \mathrm{~h}$ \\
\hline 2009/10 & 46 & 37 & 37 & 42 & 47 & 50 & 44 & 48 & 43 & 44 & $\begin{array}{l}44 \\
\text { bcd }\end{array}$ \\
\hline 2010/11 & 54 & 35 & 56 & 50 & 58 & 57 & 43 & 48 & 50 & 51 & $50 a b$ \\
\hline $2011 / 12$ & $32 a b$ & $33 a b$ & $31 \mathrm{ab}$ & $34 a b$ & $34 a b$ & $34 a b$ & $36 \mathrm{a}$ & $34 a b$ & $26 \mathrm{~b}$ & $28 \mathrm{~b}$ & 32 ef \\
\hline Média & 37 & 36 & 38 & 38 & 37 & 38 & 38 & 38 & 38 & 39 & 38 \\
\hline
\end{tabular}

1996/97: C.V.: 12\% e F.: 0,9ns; 1997/98: C.V.: 16\% e F.: 3,0*; 1999/00: C.V.: 17\% e F.: 0,7ns; 2000/01: C.V.: 19\% e F.: 0,6ns; 2001/02: C.V.: 20\% e F.: 1,9ns; 2003/04: C.V.: 19\% e F.: 1,7ns; 2004/05: C.V.: 30\% e F.: 2,0ns; 2005/06: C.V.: 30\% e F.: 0,7ns; 2006/07: C.V.: 28\% e F.: 0,3ns; 2008/09: C.V.: 28\% e F.: 0,8ns; 2009/10: C.V.: 15\% e F.: 1,5ns; 2010/11.: C.V.: 27\% e F.: 1,1ns; e 2011/12: C.V.: 10\% e F.: 3,4**ns. Sistema I: trigo/soja, ervilhaca/milho e aveia branca/soja; Sistema II: trigo/soja, pastagem de aveia preta + ervilhaca/milho e aveia branca/soja; Sistema III: pastagem perene de estação fria (festuca + trevos + cornichăo), depois produçấo de grãos; Sistema IV: pastagem perene de estaçáo quente (pensacola + trevos + cornichāo + aveia preta + azevém), depois produção de grãos; e Sistema V: alfafa, depois produção de grấos; Ab: aveia branca e T: trigo; Médias seguidas de mesma letra, minúscula na vertical e maiúscula na horizontal, nâo apresentam diferenças significativas ao nível de $5 \%$ de significância, pelo teste de Tukey; ns: năo significativo; *: nível de significância de $5 \%$; e ${ }^{* *}$ : nível de significância de $1 \%$.

Tabela 3. Número de grãos/planta de soja em sistemas de produção com integraçáo lavoura-pecuária, em Passo Fundo, RS

\begin{tabular}{|c|c|c|c|c|c|c|c|c|c|c|c|}
\hline \multirow{3}{*}{ Ano } & \multicolumn{10}{|c|}{ Sistema de produção } & \multirow{3}{*}{ Média } \\
\hline & \multicolumn{2}{|c|}{ Sistema I } & \multicolumn{2}{|c|}{ Sistema II } & \multicolumn{2}{|c|}{ Sistema III } & \multicolumn{2}{|c|}{ Sistema IV } & \multicolumn{2}{|c|}{ Sistema V } & \\
\hline & $\mathbf{A b}$ & $\mathbf{T}$ & $\mathbf{A b}$ & $\mathbf{T}$ & $\mathbf{A b}$ & $\mathbf{T}$ & Ab & $\mathbf{T}$ & $A b$ & $\mathbf{T}$ & \\
\hline \multicolumn{12}{|c|}{ Número de grãos/planta de soja } \\
\hline 1996/97 & 69 & 74 & 69 & 81 & 65 & 66 & 65 & 65 & 71 & 71 & 69 def \\
\hline $1997 / 98$ & $66 \mathrm{ab}$ & $59 a b$ & $75 a b$ & $64 \mathrm{ab}$ & $73 a b$ & $54 \mathrm{~b}$ & $73 a b$ & $67 a b$ & $87 \mathrm{a}$ & $90 \mathrm{a}$ & 70 def \\
\hline 1999/00 & 48 & 51 & 47 & 54 & 54 & 47 & 57 & 55 & 50 & 52 & $52 \mathrm{gh}$ \\
\hline $2000 / 01$ & 97 & 96 & 113 & 114 & 101 & 106 & 90 & 111 & 98 & 90 & $101 \mathrm{a}$ \\
\hline $2001 / 02$ & 97 & 122 & 82 & 101 & 80 & 84 & 81 & 92 & 73 & 91 & $90 a b$ \\
\hline $2003 / 04$ & 41 & 44 & 41 & 42 & 45 & 43 & 54 & 56 & 53 & 55 & $48 \mathrm{~h}$ \\
\hline $2004 / 05$ & 62 & 52 & 64 & 79 & 51 & 72 & 93 & 64 & 58 & 45 & $64 \mathrm{efg}$ \\
\hline $2005 / 06$ & 81 & 100 & 82 & 66 & 71 & 89 & 76 & 91 & 93 & 81 & $83 \mathrm{bcd}$ \\
\hline $2006 / 07$ & 62 & 54 & 62 & 59 & 67 & 53 & 43 & 50 & 69 & 63 & $58 \mathrm{fgh}$ \\
\hline $2008 / 09$ & 71 & 63 & 75 & 62 & 59 & 57 & 71 & 60 & 71 & 85 & 67 ef \\
\hline $2009 / 10$ & 90 & 72 & 70 & 77 & 90 & 99 & 81 & 99 & 85 & 94 & 86 bc \\
\hline $2010 / 11$ & 80 & 66 & 84 & 83 & 89 & 63 & 77 & 71 & 63 & 63 & $74 \mathrm{cde}$ \\
\hline $2011 / 12$ & 58 & 73 & 66 & 70 & 67 & 66 & 74 & 68 & 57 & 62 & 66 ef \\
\hline Média & 71 & 71 & 72 & 73 & 70 & 69 & 72 & 73 & 71 & 73 & 72 \\
\hline
\end{tabular}

1996/1997: C.V.: 12\% e F.:1,3ns; 1997/1998: C.V.: 19\% e F.: 2,1*; 1999/00: C.V.: 18\% e F.: 0,5ns; 2000/01: C.V.: 17\% e F.: 1,1ns; 2001/02: C.V.: 30\% e F.: 1,0ns; 2003/04: C.V.: 17\% e F.: 2,4ns; 2004/05: C.V.: 34\% e F.: 1,7ns; 2005/06: C.V.: 21\% e F.: 1,4ns; 2006/07: C.V.: 31\% e F.: 0,8ns; 2008/09: C.V.: 29\% e F.: 0,8ns; 2009/10: C.V.: 16\% e F.: 2,2ns; 2010/11.: C.V.: 30\% e F.: 0,8ns; e 2011/12: C.V.: 20\% e F.: 0,7ns; Sistema I: trigo/soja, ervilhaca/milho e aveia branca/soja; Sistema II: trigo/soja, pastagem de aveia preta + ervilhaca/milho e aveia branca/soja; Sistema III: pastagem perene de estação fria (festuca + trevos + cornichão), depois produção de grãos; Sistema IV: pastagem perene de estação quente (pensacola + trevos + cornichão + aveia preta + azevém), depois produção de grãos; e Sistema V: alfafa, depois produção de grãos; Ab: aveia branca e T: trigo; Médias seguidas de mesma letra, minúscula na vertical e maiúscula na horizontal, não apresentam diferenças significativas ao nível de 5\% de significância pelo teste de Tukey; ns: não significativo; $\mathrm{e}^{*}$ : nível de significância de $5 \%$. 
No estudo em discussão, houve acúmulo de matéria orgânica, de $\mathrm{P}$ extraível e de $\mathrm{K}$ trocável, principalmente na camada superficial do solo de $0-5 \mathrm{~cm}$, em relação ao preparo convencional de solo para a mesma camada anteriormente à instalação do experimento (Santos et al., 2001; 2011). Resultados semelhantes foram obtidos por Santos et al. (2009a;b) com sistemas de produção com integração lavoura-pecuária.

No experimento em estudo, nos primeiros quatro anos (de 1993 a 1998), os sistemas com leguminosas perenes (alfafa, cornichão, trevo branco e trevo vermelho) foram mais eficientes no acúmulo de matéria orgânica, apenas na

Tabela 4. Massa de grãos/planta de soja em sistemas de produção com integração lavoura-pecuária, em Passo Fundo, RS

\begin{tabular}{|c|c|c|c|c|c|c|c|c|c|c|c|}
\hline \multirow{3}{*}{ Ano } & \multicolumn{10}{|c|}{ Sistema de produção } & \multirow{3}{*}{ Média } \\
\hline & \multicolumn{2}{|c|}{ Sistema I } & \multicolumn{2}{|c|}{ Sistema II } & \multicolumn{2}{|c|}{ Sistema III } & \multicolumn{2}{|c|}{ Sistema IV } & \multicolumn{2}{|c|}{ Sistema V } & \\
\hline & $\mathbf{A b}$ & $T$ & $\mathbf{A b}$ & $\mathbf{T}$ & $\mathbf{A b}$ & $\mathbf{T}$ & $\mathbf{A b}$ & $\mathbf{T}$ & $A b$ & $\mathbf{T}$ & \\
\hline \multicolumn{12}{|c|}{ Massa de grãos/planta de soja (g) } \\
\hline 1996/97 & 9 & 10 & 10 & 11 & 8 & 8 & 8 & 9 & 9 & 8 & 9 ef \\
\hline $1997 / 98$ & $12 a b$ & $12 a b$ & $14 a b$ & $12 a b$ & $15 a b$ & $10 \mathrm{~b}$ & $15 a b$ & $13 a b$ & $17 \mathrm{a}$ & $17 \mathrm{a}$ & $13 b$ \\
\hline 1999/00 & 10 & 11 & 11 & 12 & 12 & 10 & 12 & 12 & 11 & 11 & 11 cde \\
\hline 2000/01 & 18 & 19 & 21 & 21 & 18 & 19 & 18 & 20 & 19 & 19 & $19 a$ \\
\hline $2001 / 02$ & 18 & 23 & 18 & 20 & 15 & 15 & 15 & 18 & 15 & 22 & $18 \mathrm{a}$ \\
\hline $2003 / 04$ & 7 & 8 & 7 & 7 & 7 & 8 & 9 & 9 & 9 & 9 & $8 \mathrm{f}$ \\
\hline $2004 / 05$ & 14 & 9 & 12 & 15 & 9 & 14 & 19 & 12 & 12 & 9 & 12 bc \\
\hline $2005 / 06$ & 12 & 15 & 12 & 10 & 11 & 14 & 12 & 15 & 16 & 13 & $13 b c$ \\
\hline $2006 / 07$ & 10 & 9 & 9 & 10 & 10 & 8 & 7 & 8 & 12 & 12 & 10 def \\
\hline 2008/09 & 12 & 12 & 13 & 12 & 11 & 11 & 13 & 11 & 12 & 15 & 12 bc \\
\hline 2009/10 & 14 & 12 & 11 & 12 & 15 & 16 & 13 & 15 & 14 & 15 & $13 \mathrm{~b}$ \\
\hline $2010 / 11$ & 12 & 10 & 13 & 13 & 14 & 12 & 12 & 11 & 10 & 10 & $11 \mathrm{bcd}$ \\
\hline $2011 / 12$ & 13 & 13 & 12 & 12 & 13 & 13 & 14 & 12 & 11 & 11 & $12 b c$ \\
\hline Média & 12 & 12 & 13 & 13 & 12 & 12 & 13 & 13 & 13 & 13 & 13 \\
\hline
\end{tabular}

1996/97: C.V.: 14\% e F.: 2,0ns; 1997/98: C.V.: 18\% e F.: 2,8*; 1999/00: C.V.: 19\% e F.: 058ns; 2000/01: C.V.: 19\% e F.: 0,5ns; 2001/02: C.V.: 26\% e F.: 1,6ns; 2003/04: C.V.: 17\% e F.: 2,5ns; 2004/05: C.V.: 37\% e F.: 1,7ns; 2005/06: C.V.: 24\% e F.: 1,6ns; 2006/07: C.V.: 32\% e F.: 1,3ns; 2008/09: C.V.: 28\% e F.: 0,6ns; 2009/10: C.V.: 16\% e F.: 1,9ns; 2010/11.: C.V.: 22\% e F.: 1,1ns; e 2011/12: C.V.: 11\% e F.: 3,8ns; Sistema I: trigo/soja, ervilhaca/milho e aveia branca/soja; Sistema II: trigo/soja, pastagem de aveia preta + ervilhaca/milho e aveia branca/soja; Sistema III: pastagem perene de estação fria (festuca + trevos + cornichão), depois produção de grãos; Sistema IV: pastagem perene de estação quente (pensacola + trevos + cornichăo + aveia preta + azevém), depois produçấo de grãos; e Sistema V: alfafa, depois produção de grãos; Ab: aveia branca e T: trigo; Médias seguidas de mesma letra, minúscula na vertical e maiúscula na horizontal, năo apresentam diferenças significativas ao nível de 5\% de significância pelo teste de Tukey; ns: não significativo; $e^{*}$ : nível de significância de $5 \%$.

Tabela 5. Massa de mil grãos de soja em sistemas de produção com integração lavoura-pecuária, em Passo Fundo, RS

\begin{tabular}{|c|c|c|c|c|c|c|c|c|c|c|c|}
\hline \multirow{3}{*}{ Ano } & \multicolumn{10}{|c|}{ Sistema de produção } & \multirow{3}{*}{ Média } \\
\hline & \multicolumn{2}{|c|}{ Sistema I } & \multicolumn{2}{|c|}{ Sistema II } & \multicolumn{2}{|c|}{ Sistema III } & \multicolumn{2}{|c|}{ Sistema IV } & \multicolumn{2}{|c|}{ Sistema V } & \\
\hline & $\mathbf{A b}$ & $\mathbf{T}$ & $\mathbf{A b}$ & $\mathbf{T}$ & $\mathbf{A b}$ & $\mathbf{T}$ & $A b$ & $\mathbf{T}$ & $\mathbf{A b}$ & $\mathbf{T}$ & \\
\hline \multicolumn{12}{|c|}{ Massa de mil grãos de soja (g) } \\
\hline 1996/97 & $129 a b c$ & $136 a$ & $131 \mathrm{abc}$ & $136 \mathrm{a}$ & $127 \mathrm{bc}$ & $129 a b c$ & $132 \mathrm{ab}$ & $127 \mathrm{abc}$ & $117 c$ & 119 bc & 128 e \\
\hline $1997 / 98$ & 186 & 190 & 181 & 188 & 203 & 203 & 200 & 198 & 187 & 193 & $193 b$ \\
\hline 1999/00 & 208 & 211 & 225 & 215 & 228 & 219 & 213 & 213 & 221 & 222 & $218 a$ \\
\hline $2000 / 01$ & $204 \mathrm{a}$ & $201 \mathrm{a}$ & $199 \mathrm{ab}$ & $198 a b$ & $192 \mathrm{ab}$ & $182 b$ & $191 \mathrm{ab}$ & $195 \mathrm{ab}$ & $191 a b$ & $197 a b$ & $195 \mathrm{~b}$ \\
\hline $2001 / 02$ & 193 & 189 & 188 & 197 & 171 & 183 & 192 & 193 & 208 & 198 & $191 \mathrm{~b}$ \\
\hline $2003 / 04$ & $154 a b c$ & $152 a b c$ & 146 bc & $141 \mathrm{c}$ & $159 a b$ & $159 a b$ & $153 a b c$ & $154 \mathrm{abc}$ & $165 \mathrm{a}$ & $161 \mathrm{ab}$ & $154 \mathrm{~d}$ \\
\hline $2004 / 05$ & 183 & 193 & 181 & 180 & 193 & 185 & 192 & 187 & 203 & 189 & $189 \mathrm{~b}$ \\
\hline $2005 / 06$ & 145 & 155 & 147 & 150 & 158 & 161 & 156 & 164 & 166 & 162 & $156 \mathrm{~d}$ \\
\hline $2006 / 07$ & 166 & 161 & 155 & 170 & 147 & 157 & 159 & 168 & 164 & 164 & $161 \mathrm{~d}$ \\
\hline $2008 / 09$ & 172 & 183 & 177 & 187 & 184 & 184 & 183 & 186 & 172 & 138 & $177 \mathrm{c}$ \\
\hline $2009 / 10$ & 155 & 165 & 156 & 154 & 164 & 159 & 164 & 155 & 165 & 157 & $159 \mathrm{~d}$ \\
\hline 2010/11 & 157 & 154 & 153 & 152 & 154 & 158 & 157 & 152 & 158 & 155 & $154 \mathrm{~d}$ \\
\hline $2011 / 12$ & 181 & 184 & 186 & 181 & 198 & 193 & 191 & 176 & 191 & 175 & 185 bc \\
\hline Média & 172 & 175 & 171 & 173 & 175 & 175 & 176 & 174 & 178 & 172 & 174 \\
\hline
\end{tabular}

1996/97: C.V.: 6\% e F.: 4,6**; 1997/98: C.V.: 6\% e F.: 1,9ns; 1999/00: C.V.: 9\% e F.: 0,4ns; 2000/01: C.V.: 4\% e F.: 3,0*; 2001/02: C.V.: 9\% e F.: 1,4ns; 2003/04: C.V.: 5\% e F.: 3,7**; 2004/05: C.V.: 6\% e F.: 1,7ns; 2005/06: C.V.: 6\% e F.: 2,0ns; 2006/07: C.V.: 9\% e F.: 0,9ns; 2008/09: C.V.: 14\% e F.: 1,2ns; 2009/10: C.V.: 7\% e F.: 0,8ns; 2010/11.: C.V.: 6\% e F.: 0,3ns; e 2011/12: C.V.: 7\% e F.: 1,24ns; Sistema I: trigo/soja, ervilhaca/milho e aveia branca/soja; Sistema II: trigo/soja, pastagem de aveia preta + ervilhaca/ milho e aveia branca/soja; Sistema III: pastagem perene de estaçáo fria (festuca + trevos + cornicháo), depois produçãa de grãos; Sistema IV: pastagem perene de estação quente (pensacola + trevos + cornichão + aveia preta + azevém), depois produçâo de grãos; e Sistema V: alfafa, depois produção de grãos; Ab: aveia branca e T: trigo; Médias seguidas de mesma letra, minúscula na vertical e maiúscula na horizontal, não apresentam diferenças significativas ao nível de $5 \%$ de significância pelo teste de Tukey; ns: nẫo significativo; *: nível de significância de 5\%; $\mathrm{e}^{* *}$ : nível de significância de $1 \%$. 
camada superficial do solo (sistema I: $30 \mathrm{~g} \mathrm{~kg}^{-1}$; sistema II: $28 \mathrm{~g} \mathrm{~kg}^{-1}$; sistema III: $33 \mathrm{~g} \mathrm{~kg}^{-1}$; sistema IV: $37 \mathrm{~g} \mathrm{~kg}^{-1}$; e sistema V: $32 \mathrm{~g} \mathrm{~kg}^{-1}$ ), decorrente do acúmulo de resíduos vegetais sobre a superfície do solo mantido pelo sistema de plantio direto e pela não incorporação desses por meio do revolvimento. Nos anos seguintes (2000, 2002 e 2005), a manutenção de teores de matéria orgânica (sistema I: 34 a
$44 \mathrm{~g} \mathrm{~kg}^{-1}$; sistema II: 33 a $44 \mathrm{~g} \mathrm{~kg}^{-1}$; sistema III: 37 a $45 \mathrm{~g} \mathrm{~kg}^{-1}$; sistema IV: 35 a $44 \mathrm{~g} \mathrm{~kg}^{-1}$; e sistema V: 35 a $46 \mathrm{~g} \mathrm{~kg}^{-1}$ ) foi semelhante à das culturas anuais (aveia branca, milho, soja e trigo) (Santos et al., 2011).

Na safra de 2003/2004, a soja cultivada após aveia branca e trigo no sistema $\mathrm{V}$ foi superior para rendimento de grãos em relação à soja cultivada após aveia branca e trigo nos

Tabela 6. Estatura de plantas de soja em sistemas de produção com integração lavoura-pecuária, em Passo Fundo, RS

\begin{tabular}{|c|c|c|c|c|c|c|c|c|c|c|c|}
\hline \multirow{3}{*}{ Ano } & \multicolumn{10}{|c|}{ Sistema de produção } & \multirow{3}{*}{ Média } \\
\hline & \multicolumn{2}{|c|}{ Sistema I } & \multicolumn{2}{|c|}{ Sistema II } & \multicolumn{2}{|c|}{ Sistema III } & \multicolumn{2}{|c|}{ Sistema IV } & \multicolumn{2}{|c|}{ Sistema V } & \\
\hline & $\mathbf{A b}$ & T & $A b$ & $\mathbf{T}$ & $A b$ & $\mathrm{~T}$ & $\mathbf{A b}$ & $T$ & $A b$ & $T$ & \\
\hline \multicolumn{12}{|c|}{ Estatura de plantas de soja $(\mathrm{cm})$} \\
\hline 1996/97 & 91 & 92 & 91 & 88 & 85 & 89 & 87 & 88 & 88 & 89 & $89 \mathrm{~cd}$ \\
\hline $1997 / 98$ & $74 c$ & $81 \mathrm{abc}$ & $84 a b c$ & $89 \mathrm{a}$ & 75 bc & $73 c$ & $79 a b c$ & $83 a b c$ & $83 \mathrm{abc}$ & $86 a b$ & 81 ef \\
\hline 1999/00 & 85 & 84 & 82 & 81 & 77 & 77 & 76 & 73 & 80 & 78 & $79 \mathrm{f}$ \\
\hline $2000 / 01$ & 108 & 105 & 105 & 103 & 102 & 102 & 103 & 107 & 104 & 105 & $105 a$ \\
\hline 2001/02 & 97 & 91 & 100 & 91 & 96 & 89 & 98 & 94 & 88 & 89 & $93 \mathrm{bc}$ \\
\hline $2003 / 04$ & 113 & 107 & 114 & 106 & 104 & 109 & 112 & 107 & 101 & 104 & $108 a$ \\
\hline $2004 / 05$ & 44 & 43 & 46 & 42 & 43 & 43 & 41 & 38 & 38 & 38 & $42 \mathrm{~h}$ \\
\hline $2005 / 06$ & 90 & 92 & 79 & 86 & 82 & 91 & 88 & 88 & 77 & 77 & $85 \mathrm{de}$ \\
\hline $2006 / 07$ & 106 & 100 & 106 & 105 & 105 & 98 & 109 & 110 & 104 & 102 & $104 a$ \\
\hline 2008/09 & 98 & 101 & 104 & 100 & 91 & 99 & 100 & 95 & 95 & 91 & $97 \mathrm{~b}$ \\
\hline $2009 / 10$ & 95 & 94 & 95 & 89 & 82 & 90 & 90 & 91 & 80 & 91 & $89 \mathrm{~cd}$ \\
\hline $2010 / 11$ & 104 & 104 & 104 & 104 & 105 & 106 & 106 & 114 & 103 & 106 & $105 a$ \\
\hline $2011 / 12$ & 65 & 61 & 69 & 64 & 64 & 62 & 64 & 61 & 61 & 55 & $62 \mathrm{~g}$ \\
\hline Média & 90 & 89 & 91 & 88 & 85 & 87 & 89 & 88 & 85 & 85 & 88 \\
\hline
\end{tabular}

1996/97: C.V.: 5\% e F.: 0,9ns; 1997/98: C.V.: 5\% e F.: 5,0**; 1999/00: C.V.: 7\% e F.: 1,7ns; 2000/01: C.V.: 3\% e F.: 1,0ns; 2001/02: C.V.: 7\% e F.: 1,6ns; 2003/04: C.V.: 6\% e F.: 1,8ns; 2004/05: C.V.: 11\% e F.: 1,7ns; 2005/06: C.V.: 9\% e F.: 2,3ns; 2006/07: C.V.: 8\% e F.: 0,8ns; 2008/09: C.V.: 6\% e F.: 2,4ns; 2009/10: C.V.: 8\% e F.: 2,1ns; 2010/11: C.V.: 10\% e F.: 0,4ns; e 2011/12: C.V.: $8 \%$ e F.: 2,1ns; Sistema I: trigo/soja, ervilhaca/milho e aveia branca/soja; Sistema II: trigo/soja, pastagem de aveia preta + ervilhaca/ milho e aveia branca/soja; Sistema III: pastagem perene de estação fria (festuca + trevos + cornicháo), depois produção de grấos; Sistema IV: pastagem perene de estação quente (pensacola + trevos + cornichão + aveia preta + azevém), depois produçấo de grãos, e Sistema V: alfafa, depois produção de grãos; Ab: aveia branca e T: trigo; Médias seguidas de mesma letra, minúscula na vertical e maiúscula na horizontal, não apresentam diferenças significativas ao nível de $5 \%$ de significância pelo teste de Tukey; ns: não significativo; e**: nível de significância de $1 \%$.

Tabela 7. Altura de inserção dos primeiros legumes de soja em sistemas de produção com integração lavoura-pecuária, em Passo Fundo, RS

\begin{tabular}{|c|c|c|c|c|c|c|c|c|c|c|c|}
\hline \multirow{3}{*}{ Ano } & \multicolumn{10}{|c|}{ Sistemas de Produção } & \multirow{3}{*}{ Média } \\
\hline & \multicolumn{2}{|c|}{ Sistema I } & \multicolumn{2}{|c|}{ Sistema II } & \multicolumn{2}{|c|}{ Sistema III } & \multicolumn{2}{|c|}{ Sistema IV } & \multicolumn{2}{|c|}{ Sistema V } & \\
\hline & $\mathbf{A b}$ & $\mathbf{T}$ & $\mathbf{A b}$ & $\mathbf{T}$ & $\mathbf{A b}$ & $\mathbf{T}$ & $\mathbf{A b}$ & $\mathbf{T}$ & $\mathbf{A b}$ & $\mathbf{T}$ & \\
\hline \multicolumn{12}{|c|}{ Altura de inserção dos primeiros legumes de soja $(\mathrm{cm})$} \\
\hline $1996 / 97$ & 22 & 24 & 24 & 25 & 24 & 27 & 26 & 24 & 24 & 25 & $24 c$ \\
\hline $1997 / 98$ & $18 \mathrm{ab}$ & $21 \mathrm{ab}$ & $22 a b$ & $23 \mathrm{a}$ & $16 \mathrm{~b}$ & $16 \mathrm{~b}$ & $16 \mathrm{~b}$ & $17 a b$ & $18 a b$ & $18 a b$ & $19 \mathrm{gh}$ \\
\hline 1999/00 & 14 & 15 & 14 & 16 & 15 & 15 & 14 & 13 & 14 & 14 & $14 i$ \\
\hline 2000/01 & 20 & 19 & 18 & 20 & 19 & 18 & 21 & 20 & 20 & 20 & $19 \mathrm{fg}$ \\
\hline $2001 / 02$ & 22 & 19 & 24 & 20 & 21 & 19 & 22 & 18 & 18 & 18 & 20 efg \\
\hline $2003 / 04$ & 36 & 36 & 38 & 35 & 34 & 36 & 35 & 36 & 30 & 31 & $35 a$ \\
\hline $2004 / 05$ & 9 & 10 & 10 & 10 & 10 & 9 & 8 & 10 & 6 & 9 & $9 \mathrm{j}$ \\
\hline $2005 / 06$ & 22 & 22 & 19 & 19 & 23 & 24 & 27 & 22 & 20 & 19 & 22 def \\
\hline $2006 / 07$ & 20 & 22 & 23 & 21 & 24 & 23 & 20 & 21 & 21 & 22 & $21 \mathrm{de}$ \\
\hline 2008/09 & $26 a b$ & $30 a$ & $28 a b$ & $28 a b$ & $27 a b$ & $30 a$ & $26 a b$ & $26 a b$ & $27 a b$ & $23 b$ & $27 \mathrm{~b}$ \\
\hline 2009/10 & 25 & 24 & 26 & 22 & 21 & 23 & 24 & 20 & 22 & 22 & $23 \mathrm{~cd}$ \\
\hline $2010 / 11$ & 22 & 23 & 21 & 21 & 20 & 19 & 21 & 21 & 20 & 18 & 20 efg \\
\hline $2011 / 12$ & 18 & 16 & 19 & 18 & 16 & 18 & 16 & 17 & 17 & 16 & $17 \mathrm{~h}$ \\
\hline Média & 21 & 22 & 22 & 21 & 21 & 21 & 21 & 20 & 20 & 19 & 21 \\
\hline
\end{tabular}

1996/97: C.V.: 11\% e F.: 0,7ns; 1997/98: C.V.: 13\% e F.: 3,6**; 1999/00: C.V.: 10\% e F.: 1,1ns; 2000/01: C.V.: 9\% e F.: 0,8ns; 2001/02: C.V.: 14\% e F.: 2,1ns; 2003/04: C.V.: 10\% e F.: 2,0ns; 2004/05: C.V.: 20\% e F.: 1,8ns; 2005/06: C.V.: 16\% e F.: 2,0ns; 2006/07: C.V.: 13\% e F.: 0,8ns; 2008/09: C.V.: 9\% e F.: 2,6*; 2009/10: C.V.: 13\% e F.: 1,5ns; 2010/11: C.V.: 13\% e F.: 1,4ns; e 2011/12: C.V.: 13\% e F.: 1,5ns; Sistema I: trigo/soja, ervilhaca/milho e aveia branca/soja; Sistema II: trigo/soja, pastagem de aveia preta + ervilhaca/milho e aveia branca/soja; Sistema III: pastagem perene de estação fria (festuca + trevos + cornichão), depois produção de grãos; Sistema IV: pastagem perene de estação quente (pensacola + trevos + cornichão + aveia preta + azevém), depois produção de grãos; e Sistema V: alfafa, depois produção de grãos; Ab: aveia branca e T: trigo; Médias seguidas de mesma letra, minúscula na vertical e maiúscula na horizontal, não apresentam diferenças significativas ao nível de 5\% de significância pelo teste de Tukey; ns: não significativo; $\mathrm{e}^{*}$ : nível de significância de $5 \%$. 
sistemas I e II. A soja cultivada após aveia branca e trigo nos sistemas III e IV situou-se numa posição intermediária para rendimento de grãos. O rendimento médio de grãos de soja $\left(1.830 \mathrm{~kg} \mathrm{ha}^{-1}\right)$ nessa safra agrícola foi relativamente baixo devido a forte estiagem que ocorreu no fim de fevereiro e parte de março de 2004. Porém, na safra de 2004/2005, a soja cultivada após trigo no sistema II apresentou maior rendimento de grãos em comparaçáo com a soja cultivada após aveia branca nos sistemas IV e V. Nessa safra agrícola, o rendimento médio de grãos $\left(748 \mathrm{~kg} \mathrm{ha}^{-1}\right)$ foi ainda mais baixo do que no ano anterior devido à estiagem nos meses de dezembro de 2004 e fevereiro de 2005. Nas safras de 2005/2006 e de 2006/2007, a soja cultivada após trigo nos sistemas III e V foi superior para rendimento de grãos em comparação à maioria dos demais sistemas de produção estudados. Na safra 2009/2010, a soja cultivada após trigo no sistema IV destacou-se para rendimento de grãos, em comparaçáo à soja cultivada após trigo no sistema II.

Deve ser levado em consideraçáo que no sistema I (trigo/ soja, ervilhaca/milho e aveia branca/soja) havia somente culturas produtoras de grãos desde 1993, enquanto no sistema II havia culturas produtoras de grãos e pastagem anual de inverno (trigo/soja, pastagem de aveia preta + ervilhaca/ milho e aveia branca/soja). Portanto, os resultados de rendimento de grãos de soja, nos anos 2005/2006, 2006/2007 e 2009/2010 nos sistemas III, IV e V concordam com dados frequentemente encontrados na literatura sobre melhoria das condiçôes edáficas do solo após pastagens anuais ou perenes, como leguminosas (alfafa, cornichão, ervilha, ervilhaca, trevo branco e trevo vermelho), pelo acúmulo de nutrientes na superfície do solo e, principalmente, de matéria orgânica (Boddey et al., 2010; Godsey et al., 2007; Jantalia et al., 2008; Santos et al., 2001).

Souza et al. (2009), estudando sistemas de produçáo com pastagens de aveia preta e azevém, no inverno, e cultivo de soja, no verão, em São Miguel das Missôes, RS, verificaram que a intensidade de pastejo moderado $(20$ a $40 \mathrm{~cm}$ de altura do pasto) promoveu aumento nos estoques de C orgânico (de 3,9 e 2,8 $\mathrm{Mg} \mathrm{ha}^{-1}$ para 8,2 e 7,4 $\mathrm{Mg} \mathrm{ha}^{-1}$, respectivamente) e $\mathrm{N}$ total $\left(419\right.$ e $277 \mathrm{Mg} \mathrm{ha}^{-1}$ para 718 e $570 \mathrm{Mg} \mathrm{ha}^{-1}$, respectivamente), de forma semelhante ao sistema de plantio direto.

O rendimento médio de grãos de soja no período de $1996 / 1997$ a $2011 / 2012$ foi de $2.428 \mathrm{~kg} \mathrm{ha}^{-1}$. Os maiores rendimentos médios de grãos ocorreram nas safras de $1999 / 2000\left(3.335 \mathrm{~kg} \mathrm{ha}^{-1}\right)$ e de $2000 / 2001$ (3.326 kg ha $\left.{ }^{-1}\right)$, enquanto o menor ocorreu na safra de $2004 / 2005\left(748 \mathrm{~kg} \mathrm{ha}^{-1}\right)$.

Fontaneli et al. (2000), conduzindo experimento durante seis anos, com cultivares convencionais de soja (BR 4, de 1990/2001 a 1992/1993 e BR 16 de 1993/1994 a 1995/1996), em área próxima e na regiáo de Passo Fundo, RS, em sistemas de produção com integração lavoura-pecuária, não observaram diferença no rendimento de gráos entre os tratamentos (soja após aveia branca - 2.576 e $2.736 \mathrm{~kg} \mathrm{ha}^{-1}$, soja após pastagem de aveia preta -2.628 e $2.671 \mathrm{~kg} \mathrm{ha}^{-1}$, soja após pastagem de aveia preta + ervilhaca $-2.785 \mathrm{~kg} \mathrm{ha}^{-1}$, soja após ervilhaca $-2.871 \mathrm{~kg} \mathrm{ha}^{-1}$ e soja após trigo - de 2.629 a $2.999 \mathrm{~kg} \mathrm{ha}^{-1}$ ). Na soja cultivada após oferta de pastagem com aveia preta e sem pastejo, Lopes et al. (2009) (safra de 2004/2005: média dos tratamentos: $1.223 \mathrm{~kg} \mathrm{ha}^{-1}$ ) e Ferreira et al. (2009) (nas safras de 2006/2007: média dos tratamentos: $3.500 \mathrm{~kg} \mathrm{ha}^{-1}$ e de 2007/2008 média dos tratamentos: $2.500 \mathrm{~kg} \mathrm{ha}^{-1}$ ) não encontraram diferença no rendimento de grãos de soja com a presença ou náo do animal ou entre as intensidades de pastejo utilizadas na aveia preta $(10,20,30$ e $40 \mathrm{~cm})$. Ainda, de acordo com Lopes et al. (2009), na safra de 2004/2005 ocorreu déficit hídrico de $262 \mathrm{~mm}$ em relação à média normal de 30 anos. Esses resultados indicam que o rendimento de grãos de soja não foi alterado pela presença do animal no ciclo precedente, abrindo a possibilidade de utilizaçáo de imensas áreas (2 milhôes de hectares no estado do Rio Grande do Sul) que, no período de inverno, são cultivadas unicamente com plantas de cobertura.

\section{CONCLUSÃO}

Não há diferença entre as médias dos sistemas de produção com integração lavoura-pecuária para rendimento de grãos, número de legumes por planta, número de grãos por planta, massa de grãos por planta, massa de mil gráos, estatura de plantas e altura de inserção dos primeiros legumes.

A soja pode ser cultivada após aveia branca e trigo, sem prejuízo no rendimento de grãos em sistemas de produção com pastagem de aveia preta + ervilhaca, pastagens perenes de estação fria e de estação quente e com alfafa para corte ou pastejo.

\section{REFERÊNCIAS}

AMBROSI, I.; SANTOS, H.P.; FONTANELI, R.S.; ZOLDAN, S.M. Lucratividade e risco de sistema de produçáo de grãos combinados com pastagens de inverno. Pesquisa Agropecuária Brasileira, v.36, p.12131219, 2001. http://dx.doi.org/10.1590/S0100-204X2001001000001

BALBINOT JUNIOR, A.A.; MORAES, A.; VEIGA, M.; PELISSARI, A.; DICKOW, J. Integração lavoura-pecuária: intensificação de uso de áreas agrícolas. Ciência Rural, v.39, p.1925-1933, 2009. http:// dx.doi.org/10.1590/S0103-84782009005000107

BODDEY, R.M.; JANTÁLIA, C.A.; CONCEIÇÃO, P.C.; ZANATTA, J.A.; BAYER, C.; MIELNICZUCK, J.; DIECKOW, J.; SANTOS, H.P.; DENARDIN, J.E.; AITA, C.; GIACOMINI, S.J.; ALVES, B.J.R.; URQUIAGA, S. Carbon accumulation at depth in Ferralsols under zero-till subtropical agriculture. Global Change Biology, v.16, p.784-795, 2010. http://dx.doi.org/10.1111/j.1365-2486.2009.02020.x 
FERREIRA, E.V.O.; ANGHINONI, I.; ANDRIGHETTI, M.H.; MARTINS, A.P.; CARVALHO, P.C.F. Ciclagem e balanço de potássio e produtividade de soja na integraçáo lavoura-pecuária sob semeadura direta. Revista Brasileira de Ciência do Solo, v.33, p.1675-1684, 2009. http://dx.doi.org/10.1590/S0100-06832009000600016

FLORES, J.P.C.; CASSOL, L.C.; ANGHINONI, I.; CARVALHO, P.C.F. Atributos químicos do solo em função da aplicação superficial de calcário em sistema de integração lavoura pecuária submetido a pressōes de pastejo em plantio direto. Revista Brasileira de Ciência do Solo, v.32, p.2385-2396, 2008. http://dx.doi.org/10.1590/S010006832008000600017

FONTANELI, R.S.; SANTOS, H.P.; RODRIGUES, O.; PIRES, J.L.F. Cereais de inverno de duplo propósito - Estabelecimento de manejo de cereais de duplo propósito. In: FONTANELI, R.S.; SANTOS, H.P.; FONTANELI, R.S. (Ed.). Forrageiras para integraçâo lavourapecuária-floresta na regiáo sul-brasileira. Passo Fundo: Embrapa Trigo, 2009. p.79-96.

FONTANELI, R.S.; SANTOS, H.P.; VOSS, M.; AMBROSI, I. Rendimento e nodulação de soja em diferentes rotaçôes de espécies anuais de inverno, sob plantio direto. Pesquisa Agropecuária Brasileira, v.35, p.349-355, 2000. http://dx.doi.org/10.1590/S0100204X2000000200014

GODSEY, C.B.; PIERZYNSKI, G.M.; MENGEL, D.B.; LAMOND, R.E. Changes in soil $\mathrm{pH}$, organic carbon, and extractable aluminum from crop rotation and tillage. Soil Science Society of America Journal, v.71, p.1038-1044, 2007. http://dx.doi.org/10.2136/sssaj2006.0170

JANTALIA, C.P.; SANTOS, H.P.; URQUIAGA, S.; BODDEY, R.M.; ALVES, B.J.R. Fluxes of nitrous oxide from soil under different crop rotations and tillage systems in the South of Brazil. Nutrient Cycling in Agroecosystems, v.82, p.161-173, 2008. http://dx.doi.org/10.1007/ s10705-008-9178-y

LOPES, M.L.T.; CARVALHO, P.C.F.; ANGHINONI, I.; SANTOS, D.T.; AGUINAGA, A.A.Q.; FLORES, J.P.C.; MORAES, A. Sistemas de integração lavoura-pecuária: efeito do manejo em pastagem de aveia preta e azevém anual sobre o rendimento da cultua da soja. Ciência Rural, v.39, p.1.499-1506, 2009.

POTES, M.L.; DICK, D.P.; DALMOLIN, R.S.D.; KNICKER, H.; ROSA, A.S. Matéria orgânica em Neossolo de altitude: influência do manejo da pastagem na sua composição e teor. Revista Brasileira de Ciência do Solo, v.34, p.23-32, 2010. http://dx.doi.org/10.1590/ S0100-06832010000100003

SANTOS, H.P.; FONTANELI, R.S.; SPERA, S.T. Rendimento de grãos de soja em sistemas de produção de grãos com pastagens anuais de inverno e perenes, sob plantio. Pesquisa Agropecuária Gaúcha, v.10, p.35-45, $2004 a$.
SANTOS, H.P.; FONTANELI, R.S.; SPERA, S.T.; DREON, G. Fertilidade e teor de matéria orgânica do solo em sistemas de produçáo com integração lavoura e pecuária sob plantio direto. Revista Brasileira de Ciências Agrárias, v.6, p.474-482, 2011. http://dx.doi.org/10.5039/ agraria.v6i3a1266

SANTOS, H.P.; FONTANELI, R.S.; SPERA, S.T.; FONTANELI, R.S.; TOMM, G.O. Atributos químicos e física de solo sob pastagens perenes de verão, v.68, p.1037-1046, 2009a. http://dx.doi.org/10.1590/ S0006-87052009000400025

SANTOS, H.P.; FONTANELI, R.S.; SPERA, S.T.; MALDANER, G.L. Rendimento de grãos em diferentes sistemas de produção integração Lavoura-pecuária. Revista Brasileira de Ciências Agrárias, v.8, p.49-56, 2013. http://dx.doi.org/10.5039/agraria.v8i1a2077

SANTOS, H.P.; FONTANELI, R.S.; SPERA, S.T.; TOMM, G.O. Efeito de sistemas de produçáo integraçáo lavoura-pecuária (ILP) sobre a fertilidade do solo em plantio direto. Acta Scientiarum Agronomy, v.31, p.719-727, 2009b. http://dx.doi.org/10.4025/actasciagron. v31i4.925

SANTOS, H.P.; FONTANELI, R.S.; TOMM, G.O. Efeito de sistemas de produção de grãos e de pastagens sob plantio direto sobre o nível fertilidade do solo após cinco anos. Revista Brasileira de Ciência do Solo, v.25. p.645-653, 2001.

SANTOS, H.P.; FONTANELI, R.S.; TOMM, G.O. Rendimento da soja em sistemas de produção de grãos com pastagens anuais de inverno e de verão, sob plantio. Pesquisa Agropecuária Gaúcha, v.10, p.47-57, $2004 b$.

SAS INSTITUTE. SAS system for Microsoft Windows. Version 9.2. Cary: SAS Institute, 2008.

SOCIEDADE BRASILEIRA DE CIÊNCIA DO SOLO - SBCS. Comissão de Química e Fertilidade do Solo. Manual de adubação e de calagem para os estados do Rio Grande do Sul e de Santa Catarina. 10. ed. Porto Alegre: SBCS/CQFS/NRS, 2004. 400p.

SOUZA, E.D.; COSTA, S.E.V.G.A.; ANGHINONI, I.; CARVALHO, P.C.F.; ANDRIGUETI, M.; CAO, E. Estoques de carbono orgânico e de nitrogênio no solo em sistema de integração lavoura-pecuária em plantio direto, submetido a intensidade de pastejo. Revista Brasileira de Ciência do Solo, v.33, p.1829-1836, 2009. http://dx.doi.org/10.1590/ S0100-06832009000600031

STRECK, E.V.; KÄMPF, N.; DALMOLIN, R.S.D.; KLAMT, E.; NASCIMENTO, P.C.; SCHNEIDER, P.; GIASSON, E.; PINTO, L.F.S. Solos do Rio Grande do Sul. 2. ed. Porto Alegre: Emater/RS; 2008. 222p. PMCid:PMC3214966 